\title{
Desastre e território: a produção da vulnerabilidade a desastres na cidade de Blumenau/SC
}

\author{
Disaster and territory: the production of vulnerability to disasters \\ in the city of Blumenau/SC
}

Maria Roseli Rossi Avila, Marcos Antonio Mattedi

Universidade Regional de Blumenau (FURB), Programa de Pós-graduação em Desenvolvimento Regional (PPGDR),

Blumenau, SC, Brasil

\section{Resumo}

Este trabalho aborda a relação entre território, desastre e desenvolvimento. Os desastres constituem uma das questões mais desafiadoras para a compreensão e o desenvolvimento do território. Compreendem, ao mesmo tempo, um obstáculo para o desenvolvimento e, também um resultado do desenvolvimento socioeconômico da região. 0 estudo discute a relação entre desastre, território e desenvolvimento regional, além de partir da hipótese de que os desastres são territorializados e têm relação com a forma de ocupação do espaço e com o desenvolvimento socioeconômico da região de forma desigual. 0 foco do estudo foi uma das comunidades de Blumenau, Santa Catarina, mais atingidas pelo desastre socioambiental ocorrido na região do Vale do Itajaí em 2008. Este trabalho divide-se em quatro partes principais: 1) desastre e território, tratando das relações entre desenvolvimento regional e desastre; 2) o desastre de 2008; 3) o caso da comunidade da Rua Pedro Krauss Sênior em Blumenau; 4) a gestão do risco de desastres.

Palavras-chave: Desenvolvimento. Região. Território. Desastres.

\section{Abstract}

This paper discusses the relation between territory, disaster and development. Disasters are one of the most challenging issues for understanding the territory and its development. Comprehend, at the same time, an obstacle to development and a result of the socioeconomic development of the region. This study discusses the relation between disaster, territory and regional development. It is based on the assumption that disasters are territorialized and related to the form of occupation of space and the socioeconomic development of the region unevenly. The focus of this study was one of the most affected communities of Blumenau, Santa Catarina, by the socioenvironmental disaster, in the region of Vale do Itajaí in 2008. This work is divided into four main parts: 1) disaster and territory - the relation between regional development and disaster; 2) the 2008 disaster; 3) the case of the community of Peter Krauss Senior Street in Blumenau; and 4) the management the risk disaster.

Keywords: Development. Region. Territory. Disasters.

MRRA é assistente social, doutoranda no Programa de Pós-graduação em Desenvolvimento Regional (PPGDR), Universidade Regional de Blumenau (FURB), e-mail: mariaroselirossiavila@yahoo.com.br

MAM é sociólogo, doutor em Ciências Sociais pela Universidade Estadual de Campinas (UNICAMP) e estágio Pós-doutoral no Centre de Sociologie de L'innovation - EMMP/Paris, professor e coordenador do Programa de Pós-graduação em Desenvolvimento Regional (PPGDR), Universidade Regional de Blumenau (FURB), e-mail: mattediblu@gmail.com 


\section{Introdução}

A questão dos desastres em Blumenau, no Estado de Santa Catarina, tem sido objeto de muitos estudos. Nas áreas das ciências naturais, como a hidrologia (Frank \& Sevegnani, 2009), a engenharia ambiental (Tachini, 2009), a meteorologia (Severo, 2009; Samagaia \& Angioni, 2009), a geologia e a geografia (Aumond \& Sevegnani, 2009), ou das ciências sociais, como a sociologia (Mattedi, 1999), a antropologia (Walter, 2008), a economia (Wagner, 2009), as ciências políticas (Schiochet, 2009; Bohn et al., 2009) e o serviço social (Samagaia, 2010; Santos, 2012), diversas pesquisas têm sido realizadas. No entanto, a reflexão sobre as dimensões territoriais do desastre permanece pouco explorada, evidenciando a necessidade de produção científica. Este trabalho aborda a relação entre território e desastre. Não se trata de uma revisão teórica, mas da tentativa de compreensão de um caso particular a partir da construção de um modelo teórico com base na integração do estudo dos desastres na temática do território.

0 trabalho divide-se em quatro partes principais: 1) desastre e território: as relações entre desenvolvimento regional e desastre; 2 ) tragédia anunciada: o desastre de novembro de 2008 em Blumenau; 3) território do desastre: a comunidade da Rua Pedro Krauss Sênior em Blumenau (uma das mais atingidas pelo desastre de novembro 2008 ocorrido no Vale do Itajaí/SC); 4) a gestão do risco de desastres. Nas considerações finais, elencamos indicativos que possam subsidiar e ampliar o debate sobre os desastres tanto no meio científico e comunitário como no âmbito da gestão.

\section{Desastre e território: as relações entre desenvolvimento regional e desastre}

Para abordar as relações entre desenvolvimento regional e desastre, faz-se necessário apresentar as referidas categorias teóricas. Com recorrência ouvimos falar em enchentes, secas, tornados, ventanias etc. Eventos dessa natureza sempre ocorreram, mas, para que existam situações de emergência, faz-se necessário considerar o impacto deles sobre determinada população (Hewitt \& Burton, 1971), ou seja, ameaças só se transformam em desastres a partir da existência da variável humana. 0 impacto está ligado à vulnerabilidade da população impactada.
Esta é construída socialmente e decorre de uma série de fatores, tais como: ocupação do território, desenvolvimento socioeconômico da região, decisões e ações (individuais/população e dos governos) em nível municipal, estadual, nacional e internacional. O Marco de Hyogo define vulnerabilidade como "Condições determinadas por fatores ou processos físicos, sociais, econômicos e ambientais que aumentam a suscetibilidade de uma comunidade ao impacto de riscos [...]" (ONU, 2015, p. 4).

Portanto, as estruturas locais, comunitárias, sociopolíticas e culturais são importantes. Destacam-se os valores, os costumes, as relações de parentesco, as redes comunitárias e familiares, e os sistemas de liderança (Dauphiné \& Provitolo, 2013). Estas têm grande influência nas representações e na percepção do desastre. Se a percepção do desastre se der a partir da perspectiva natural, a tendência é naturalizá-lo, assim como as suas consequências. Os desastres estão relacionados também a componentes culturais e sociais. Em algumas sociedades, há grandes diferenças na vulnerabilidade a desastres devido às relações desiguais de poder e às práticas tradicionais e culturais. Em outras palavras, o contexto cultural influencia na percepção do desastre (ISDR, 2004).

Questões de classe, gênero e idade passam a ter importância nesse debate. Homens, mulheres e crianças apresentam diferentes papéis e necessidades em distintos contextos sociais. Relações de poder e funções também se diferenciam (Phillips et al., 2010). As atividades econômicas das mulheres são menos visíveis que as dos homens, mas ambos são responsáveis por cuidar das crianças, idosos, deficientes e doentes, podendo limitar saídas e prejudicar a sobrevivência no contexto de um desastre. Relações de dependência e de vulnerabilidade por sexo, assim como diferenças nos papéis reprodutivos, comprometem a participação na tomada de decisões sobre a gestão das ameaças e riscos, aumentando a vulnerabilidade aos desastres de mulheres e crianças, e influem também na forma de perceber e compreender o risco (ISDR, 2004).

A percepção do que é o risco define atitudes de enfrentamento. Mattedi (1999, p. 42) relaciona o risco ao perigo e afirma que, "[...] enquanto o risco pode ser considerado o resultado de uma decisão, o perigo relaciona-se somente aos efeitos provocados por fatores que estariam fora do controle [...]". No Marco de Sendai (ONU, 2015, p. 3), perigo é definido como sendo um: 
[...] fenômeno ou atividade humana potencialmente prejudicial que pode causar a perda de vidas humanas ou ferimentos, danos à propriedade, ruptura social e econômica ou degradação ambiental. Os perigos incluem condições latentes que podem representar ameaças futuras e podem ter diferentes origens: naturais (geológicas, hidrometeorológicas e biológicas) ou induzidas por processos humanos (degradação ambiental e perigos tecnológicos).

Ao diferenciar risco e perigo, Beck (1997, p. 17) afirma que no risco "[...] começam a tomar corpo as ameaças produzidas até então no caminho da sociedade industrial [...]". Já o perigo é considerado "sempre uma construção cognitiva e social". Conforme o Marco de Hyogo, "El riesgo de desastre surge cuando las amenazas/peligros interactúan con factores de vulnerabilidad físicos, sociales, económicos y ambientales" (UNISDR, 2005, p. 7). Conceitualmente, desastre:

[...] abarca los desastres causados por amenazas de origen natural y los desastres y riesgos ambientales y tecnológicos conexos. Refleja, por tanto, un enfoque integral de la gestión del riesgo de desastres que prevé amenazas múltiples y la posible relación entre ellos, que puede tener importantes consecuencias en los sistemas sociales, económicos, culturales y ambientales (UNISDR, 2005, p. 6).

Essas consequências se traduzem em vulnerabilidade, que é "[...] a condição própria de um sistema que, em interação com a magnitude de um evento, produz os efeitos adversos, medidos em termos de intensidade dos danos prováveis [...]" (Mattedi et al., 2009, p. 15). A vulnerabilidade é construída histórica e socialmente, e passa pelo desenvolvimento socioeconômico e territorial do município ou região (Collins, 2009).

A região, para Brandão (2004, p. 62), é resultante "[...] da operação dos processos de operacionalização e diferenciação materiais da sociedade." 0 autor fala em problematizar articulações e potencialidades dos territórios, buscando visualizar problemas e alternativas para o desenvolvimento regional. A palavra região, para Costa Gomes (1995), deriva do latim regere (Regione). Conforme o autor, região é um conceito que funda uma reflexão política de base territorial e que é sempre uma discussão entre os limites da autonomia e um poder central. Sua essência é o fundamento político, de controle e de gestão de um território. 0 autor, ao citar Milton Santos (1978), define região como "[...] a síntese concreta e histórica desta instância espacial ontológica dos processos sociais, produto e meio de produção e reprodução de toda a vida social [...]" (Costa Gomes, 1995, p. 66). Para Milton Santos (1994, p. 110), essa instância espacial "comporta [...] o espaço como conjunto contraditório, formado por uma configuração territorial e por relações de produção, relações sociais." A partir dessa concepção, o "[...] espaço ganha uma espessura, uma teia de significações de experiências, isto é, a região define um código social comum que tem uma base territorial [...]" (Costa Gomes, 1995, p. 67).

Essa base territorial, para Brandão (2004), não é um local, um sítio situado, mas uma construção social conflituosa, uma produção coletiva dinâmica e multidimensional, com trajetória histórica em aberto. Nesse território, cada problema tem sua escala espacial específica. Portanto, faz-se necessário explicitar os conflitos de interesse, construir coletivamente as políticas públicas, tratar de forma criativa níveis, escalas e esferas, politizar as relações e construir cidadania em prol do desenvolvimento socioterritorial sustentável.

Para Mattedi (2015), o território encontra-se em constante construção e movimento, ou seja, território é o resultado da mudança no tempo em um determinado espaço ou lugar (Figura 1).

O ritmo ou o processo dessa mudança (desenvolvimento) pode ser rápido ou lento, e a dimensão do espaço ou

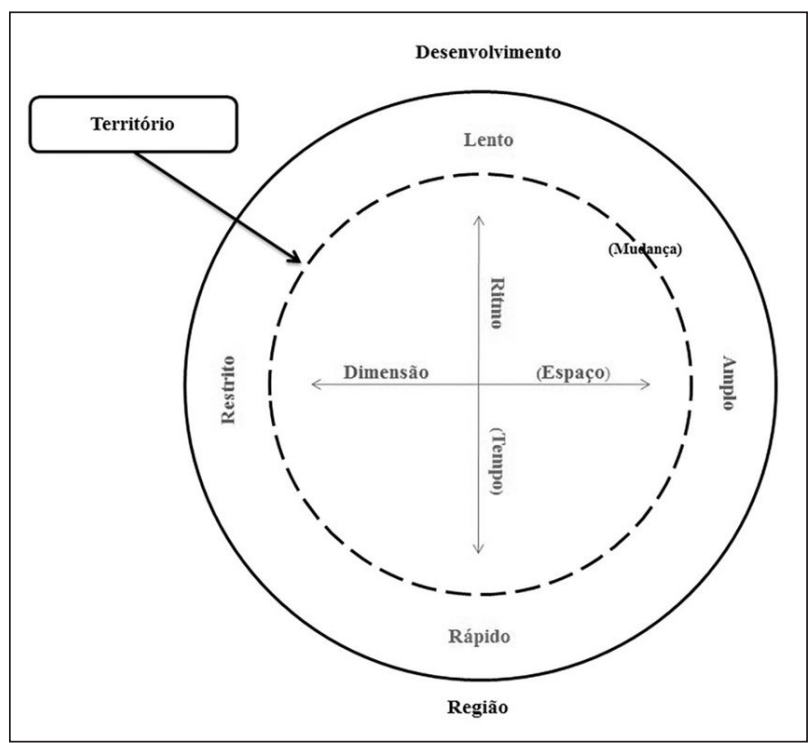

Figura 1 - Desenvolvimento $<>$ Região $=$ Território Fonte: Elaboraçã̃o dos autores (2015). 
do lugar onde a mudança ocorre pode ser ampla ou restrita. Quanto mais equilibrado o ritmo da mudança, mais equilibrado o desenvolvimento. Para o autor, “[...] quanto mais se desenvolve uma região, maiores são as interconexões e interdependências entre desenvolvimento e região [...]" (Mattedi, 2015, p. 64).

0 processo de desenvolvimento de um território ou região deve promover a ativação de recursos materiais e simbólicos, assim como a mobilização de sujeitos sociais e políticos, afirma Brandão (2004). Deve ampliar o campo de ação e as potencialidades das coletividades, aumentando sua autodeterminação, inserção nos processos decisórios e autonomia. 0 verdadeiro desenvolvimento exige envolvimento e legitimação de ações disruptivas e emancipatórias. Esse processo envolve tensões, conflitos, eleição e construção de alternativas e trajetórias históricas com horizontes temporais de curto, médio e longo prazo. Brandão enfatiza que essa construção social deve ser inclusiva de populações marginalizadas, endogeneizadora de centros de decisão e ter sustentabilidade ambiental. Sua promoção deve dar-se em várias escalas e dimensões, com políticas de desenvolvimento que pensem o território como um todo sistêmico, buscando reduzir disparidades e o fosso entre as regiões.

Uma das regiões mais afetadas pelo desastre de 2008 que ocorreu no Estado de Santa Catarina é a região de Blumenau. A cidade foi fundada em 2 de setembro de 1850 por 17 colonos europeus, liderados por Hermann Otto Blumenau. Atualmente, a população estimada do município é de 334.002 mil habitantes em um território de 519,8 km² (IBGE, 2014). A cidade localiza-se no Médio Vale do Itajaí, a nordeste do Estado de Santa Catarina, na bacia hidrográfica do rio Itajaí-Açu (Guia Santa Catarina, 2013). 0 relevo da bacia indica grande complexidade geoecológica. Os colonos procuraram adaptar as práticas agrícolas europeias à região. No entanto, o solo e o clima não eram favoráveis (Siebert, 2009). As formas de utilização dos recursos adotadas e o sistema de rotação primitiva de terras exigiram desmatamento e queimadas. Com isso, a terra foi desgastada pelos cultivos sucessivos, visando garantir a subsistência.

A colônia estabeleceu-se no vazio demográfico entre o Litoral, ocupado por vicentistas, e o Planalto do Estado, por paulistas. A área escolhida era habitada por índios Kaigangs, Xoklengs e Botocudos - então expulsos de seu território. A região é suscetível a transbordamentos do rio por tratar-se de área de várzea.
A escolha do leito secundário do Itajaí-Açu deu-se pelo tipo de povoamento baseado no assentamento da população, seguindo a orientação do rio. Os lotes foram divididos "[...] em fatias estreitas e compridas, paralelas entre si e perpendiculares aos cursos d'água [...]" (Siebert, 2009, p. 42). A forma de divisão garantia segurança, água para o plantio, para o consumo dos colonos e a comunicação via navegação.

Essa forma de distribuição de terras, adotada para áreas rurais, denominava-se Waldhüfen (linha da floresta), muito usada no leste da Alemanha, na Idade Média. 0 modelo urbano chamava-se Stadplatz (lugar da cidade), no qual os colonos residiam próximos aos cursos d'água e deslocavam-se para os lotes destinados à agricultura, mais afastados. Com o desenvolvimento urbano, foram surgindo estradas ao longo das glebas, e, com elas, o modelo Strasserdorf, que assentava os colonos em suas próprias terras (Mattedi, 1999).

Os espaços rurais foram pensados a partir do padrão Minimale Ackerbabrung, que concebia, para uma família, uma mínima quantidade de terra, suficiente apenas às condições de reprodução socioeconômica. 0 modelo permitia a formação de mais lotes e fez surgir empresas colonizadoras. Os colonos tinham seis meses para fazer o roçado, o plantio e a construção da casa, ou então devolver as terras. O Strasserdorf dava suporte ao comércio agrícola e apoio aos que residiam longe da área urbana. As povoações que foram se estabelecendo ao longo das estradas deram origem a novas cidades. Assim, iniciavam-se os processos de industrialização e de urbanização.

0 processo de industrialização passou por três fases: a primeira, 30 anos após o início da povoação, com uma malharia e duas tecelagens, indo até o advento da eletricidade e das fábricas de fiação elétrica. Com o início da guerra (1914-1918), as primeiras indústrias consolidaram-se, iniciando a segunda fase. A valoração dos produtos artesanais agrícolas aflorou, assim como pequenas fábricas de tecidos, cadarços, chapéus, gaitas de boca e móveis. Blumenau tornou-se centro de atrações na região. Com a década seguinte (1930-1940), marcada pela crise industrial de 1929, iniciou-se a terceira fase. Instalaram-se fábricas de gaze farmacêutica, aço e peças de aço. Blumenau possuía banco próprio e já era considerada metrópole regional (Mamigonian, 1966).

A guerra de 1945 trouxe evolução para a região com a chegada de novos imigrantes mais qualificados. Surgiram novas fábricas, como as de tabaco, balões de borracha, cristais, porcelana, e a independência 
técnica. 0 desenvolvimento econômico criou uma nova divisão social do trabalho e estabeleceu um novo padrão econômico e de consumo na relação mercado e indústria (Mamigonian, 1966). Devido ao aproveitamento da força hidráulica na produção, a localização das indústrias se deu próxima aos rios, e a população foi se instalando nos arredores destas. Surgiram as primeiras situações de emergência. Com o adensamento urbano e o advento das grandes enchentes, ocorreu a verticalização das construções.

Esta, se apresentou como um novo modelo de urbanização para as classes médias. Mas, para "[...] a população de baixa renda, que não pode arcar sozinha com o custo de apartamentos, a opção [...] foi subir os morros em sistema de autoconstrução [...]" (Siebert, 2009, p. 48). Conforme o Plano Municipal de Habitação de Interesse Social (Blumenau, 2012), Blumenau possui 55 assentamentos precários, dos quais a grande maioria em morros e áreas de risco. Desde o início da colonização, a "[...] constituição do espaço urbano, assim como as decisões políticas sobre a forma de utilização do solo, foram as principais causas da forma 'desordenada' de ocupação e da exposição sensível de grande parte da população aos desastres [...]" (Samagaia, 2010, p. 102). Evidencia-se, assim, uma relação entre desenvolvimento regional e desastre. 0 desenvolvimento socioeconômico produz o território do desastre - marcado pela assimetria entre a parcela rica e a parcela pobre da cidade -, região de prováveis futuras tragédias.

\section{Tragédia anunciada: 0 desastre de novembro de 2008 em Blumenau}

Em novembro de 2008, o Vale do Itajaí foi assolado por índices altíssimos de chuva. Precipitações, inundação, enxurradas, escorregamentos e movimentos de massas transformaram o Vale em campo de guerra ${ }^{1}$. Foram atingidos "[...] mais de 1,5 milhão de catarinenses, dos quais 135 mortos e cerca de 80.000 desabrigados ou desalojados [...]" (Queiroz, 2009, p. 9). No total, 14 municípios decretaram estado de calamidade

\footnotetext{
${ }^{1}$ Eventos semelhantes ocorreram em janeiro de 2011 em Nova Friburgo e Teresópolis, no Rio de Janeiro. Conforme Salatiel (2011), até o dia 18, “Chuvas intensas que caíram na região serrana do Rio [...] provocaram o pior deslizamento da história do Brasil. [...] o número de mortos chegava a 710 em quatro cidades. Outras 7.780 pessoas [...] desalojadas [...] 6.050 desabrigadas. [...] 207 [...] desaparecidas."
}

pública, e 63, situações de emergência. As consequências mais funestas ocorreram na região do Vale. As causas da destruição foram: 1) a "sobrecarga da capacidade assimilativa e regenerativa do ambiente natural"; 2) a "incapacidade cognitiva de identificar as causas"; 3) a "incapacidade política de formular e implementar estratégias de previsão e preparação para conviver com o problema”; 4) "o processo de gestão autoritário de formulação e implantação de políticas públicas que exclui a participação da sociedade organizada" (Mattedi et al., 2009, p. 17). Outros fatores, de ordem física e geológica, também contribuíram para o agravamento do desastre: a “[...] topografia acidentada; geologia frágil; precipitação intensa e prolongada que saturou o solo; e ocupação desordenada [...]" (Siebert, 2009, p. 49). As primeiras são naturais, mas a ocupação desordenada é uma ação humana, demonstrando que ambas (naturais e sociais) se entrelaçaram e criaram a situação propícia para o desastre.

0 nível do rio Itajaí-Açu alcançou 11,52 m. A enchente foi agravada pela intensa precipitação, combinada com enxurradas, escorregamentos e deslizamentos. Em Blumenau, em torno de 103 mil pessoas foram atingidas, com 5.209 desabrigados (Mattedi et al., 2009). Valêncio et al. (2007) chamam os sujeitos atingidos pelo desastre de "desestabilizados". Para os autores, um desastre atinge a família em suas vulnerabilidades, desestabilizando-a, desenraizando-a de seu espaço de elaboração do processo de viver: "[...] um processo que descaracteriza a família por retirá-la do lugar onde estava situada, o espaço onde elaborava o processo de viver, no âmbito privado e comunitário [...]" (Valêncio et al., 2007, p. 84). A partir desse conceito é possível percebermos o grau de impacto que o desastre de 2008 causou sobre a população atingida.

Dados estatísticos apontam que em Blumenau 25 mil pessoas foram alojadas em casas de vizinhos, parentes e amigos, 2.383 foram feridas e 24 perderam a vida. "Mais de 18 mil casas, 38 unidades de saúde, 61 unidades de ensino, centenas de quilômetros de rodovias e suas pavimentações foram danificadas pelos escorregamentos e inundações [...]" (Sevegnani et al., 2009, p. 113). A cidade mergulhou no caos. Literalmente parou.

Os sistemas públicos de abastecimento de água e energia faliram; vias e estradas foram interditadas; o transporte coletivo e o fornecimento de gás foram interrompidos; o ensino público foi paralisado; a 
saúde suspendeu o atendimento rotineiro para focar na emergência. 0 serviço de resgate aéreo contou com 21 aeronaves e um avião. Mil e duzentas e quarenta e nove pessoas foram resgatadas em um período de 12 dias. "Os flagelados, feridos, doentes, desesperados, molhados e desabrigados foram retirados dos locais em risco e transportados para pontos de onde eram encaminhados para diferentes abrigos [...]", que somam mais de 60 unidades (Sevegnani et al., 2009, p. 116).

Passada a fase crítica, muitas casas foram liberadas pela Defesa Civil para seus moradores. Outros, no entanto, permaneceram em abrigos. Quatro meses depois foram transferidos para moradias provisórias ${ }^{2}$ (Samagaia \& Angioni, 2009). O Governo Estadual destinou o Auxílio Reação, regulamentado pela Medida Provisória no 148, de 17 de dezembro de 2008. Os recursos eram provenientes das doações recebidas da sociedade pela Defesa Civil Estadual. Esse auxílio, no valor de $\mathrm{R} \$ 415,00$, destinava-se ao pagamento de aluguel por um período de seis meses. Toneladas de donativos nacionais e internacionais chegaram a Blumenau (Schiochet, 2009). "Foram doados 4,3 milhões de quilos de alimentos, 2,5 milhões de litros de água, 1 milhão de quilos de roupas e calçados. [...] brinquedos, materiais de limpeza e de uso pessoal [...]" (Sevegnani et al., 2009, p. 125). Até 17 de abril de 2009, R\$ 34 milhões haviam sido doados à Defesa Civil Estadual (Schiochet, 2009).

Parte dos recursos foi utilizada para implantar o Auxílio Reação; a outra foi transferida aos municípios atingidos para a aquisição de terrenos destinados a projetos habitacionais. Um desses projetos é o Programa Minha Casa Minha Vida (PMCMV), que:

[...] é financiado pelo Fundo de Arrendamento Residencial. É um programa Federal com parceria dos estados e municípios, gerido pelo Ministério das Cidades e operacionalizado pela CEF. O objetivo do Programa é a produção de unidades habitacionais vendidas, sem arrendamento prévio, às famílias com renda familiar mensal de até $\mathrm{R} \$ 1.600,00$ (PMCMV, 2013).

Desse fundo, Blumenau, naquela época com um déficit habitacional de 3 mil moradias, recebeu o montante de $\mathrm{R} \$ 8,2$ milhões. 0 desastre também mobilizou os poderes legislativos: em nível federal, foi criado o "Fórum Parlamentar Catarinense" e a

\footnotetext{
${ }^{2}$ Galpões construídos pela Prefeitura Municipal para abrigar famílias que perderam suas moradias no desastre.
}

"Comissão Externa de Acompanhamento da Tragédia Climática em Santa Catarina”, e em nível estadual, o "Fórum Permanente de Solidariedade e pela Reconstrução das Cidades Atingidas pelas Enchentes e Enxurradas de 2008". O objetivo era fiscalizar e acompanhar a aplicação dos recursos financeiros no Estado (Schiochet, 2009).

Após o desastre, suplementos em jornais, publicações eletrônicas em blogs e redes sociais, reportagens, artigos, dissertações, teses e livros foram publicados. Dentre os livros destacam-se: Desastre de 2008 no Vale do Itajaí: água, gente e política (Frank \& Sevegnani - orgs), escrito por especialistas de diferentes áreas do conhecimento da Fundação Universidade Regional de Blumenau (FURB); Relatos de um desastre: narrativas jornalísticas da tragédia de 2008 em Santa Catarina, organizado pela Defesa Civil Estadual e o Centro de Estudos e Pesquisas sobre Desastres da Universidade Federal de Santa Catarina; Relatos de uma tragédia, de Jota Aguiar; Diário de uma tragédia, de Maristela Pereira; A tragédia do Morro do Baú, de Geraldo Menezes, Relatos de um desastre, de Ana Paula Benatti (JM, 2009).

No meio científico, especialistas já citados estudam a problemática e possuem produção na área. No entanto, em Blumenau, o conhecimento científico ainda não é incorporado pela gestão política dos desastres, ou seja, não há interface entre a esfera municipal e o Departamento de Geologia e o Núcleo da FURB. Essa integração às políticas de gestão faria diferença em regiões de grande vulnerabilidade e risco, como a comunidade Pedro Krauss.

\section{Território do desastre: a comunidade da rua Pedro Krauss Sênior em Blumenau}

Para compreender o impacto do desastre sobre uma determinada população, é importante conhecer seu contexto comunitário e urbano. A comunidade Pedro Krauss é uma área de ocupação irregular, rodeada por morros e terrenos inclinados e, devido à sua localização geográfica, a localidade é considerada área de risco geológico ${ }^{3}$. Uma série de fatores (econômicos, sociais

\footnotetext{
${ }^{3}$ Estudos geológicos realizados na comunidade identificaram a ocorrência de 32 movimentos de massa de média e elevada magnitude. Os principais agentes predisponentes constatados foram: a) os complexos geológico e morfológico, b) a gravidade (declividade acentuada) e c) o clima (SEPLAN, 2010a, p. 5).
} 
e culturais) somam-se ao risco geológico, expondo a comunidade permanentemente ao risco de desastres.

Em 18 de agosto de 1961, a localidade recebeu o nome da sua principal via de acesso, Rua Pedro Krauss Sênior, em homenagem ao neto do antigo dono das terras. Antes, a via chamava-se Rua das Cabras e, depois, Rua Chapecó. Parte dos moradores é proveniente "[...] do Vale do Itajaí, planalto catarinense, Sul e Oeste de Santa Catarina. Uma pequena parcela veio de outros estados - SP e PR [...]" (Avila \& Samagaia, 2013, p. 7). Em 1949, a comunidade recebeu parte dos moradores da Favela Farroupilha, composta por 102 famílias. Conforme Avila et al. (2014, p. 1):

Quando se aproximavam as comemorações do centenário (1950) da colonização alemã do município, uma Comissão instituída pela Câmara de Vereadores recomendou - e o prefeito municipal acatou - a remoção dos moradores da comunidade, a qual foi dividida e transferida para duas regiões mais afastadas e precárias, as ruas Araranguá e Pedro Krauss Sênior. A origem da Favela Farroupilha está ligada à vinda para Blumenau de trabalhadores imigrantes para construir uma estrada de ferro. Sem condições financeiras, autoconstruíram suas moradias junto ao próprio local de trabalho.

A Favela Farroupilha, cuja população era negra, localizava-se às margens do Rio Itajaí-Açu, ao lado da ponte Aldo Pereira de Andrade, mas fez-se a transferência por motivos puramente estéticos (Avila et al., 2014, p. 3). Parte dessa população foi transferida para a comunidade Pedro Krauss, situada na Macrorregião Sul da cidade, no Bairro Vorstadt. A Figura 2 localiza visualmente a localidade no mapa do município em área de alta suscetibilidade a escorregamentos.

Na comunidade, residem hoje em torno de 800 famílias, distribuídas em área urbana e rural, totalizando $636.755,95 \mathrm{~m}^{2}$ (Blumenau, 2012). Muitos residem em locais acessíveis somente por meio de escadarias. Na Figura 3, é possível ver a distribuição espacial da localidade. A área circulada aponta o local da comunidade, de onde 40 famílias foram retiradas e posteriormente levadas para abrigos municipais (Blumenau, 2008). Os motivos foram deslizamentos ocorridos no dia anterior à transferência (16/11/2008) devido às intensas chuvas que já caíam no município. A retirada foi preventiva, pois, nos dias 22 e 23 de novembro de 2008, o município foi assolado pela maior tragédia já registrada em sua história. Reportagens do dia registravam: "O Flagelo das chuvas: tempo castiga a região" (Waltrick, 2008).

Na comunidade, inúmeras casas foram destruídas ou interditadas pela Defesa Civil. Se as 40 famílias não tivessem sido retiradas no dia 17 de novembro, as perdas humanas seriam catastróficas. Assim, estão comprovados o princípio de continuidade dos desastres e a necessidade de ações efetivas para que retiradas e realocações dos moradores de áreas de risco ocorram a tempo. Conforme fontes da Secretaria de Geologia e dados da carta de uso recomendado do solo (Figura 4), 85\% da área da comunidade é considerada de alto risco.

A intensidade da destruição alterou a geografia socioespacial e territorial da localidade. Inúmeras famílias não residem mais no local. As dependências da Igreja Católica foram parcialmente atingidas, e o estabelecimento onde funcionava a escola, totalmente destruído. As perdas se estenderam a bens como móveis, roupas, documentos e outros pertences pessoais. Após o caos, a comunidade recebeu socorro, apoio e ajuda para reerguer-se. A solidariedade veio dos próprios moradores, com ajuda do exército, da Defesa Civil, da Assistência Social do município e de outros voluntários.

No entanto, com o tempo, o abandono é sentido. A comunidade "anda esquecida" pelo poder público (Wagner, 2013). Após o desastre, praticamente nada foi feito no local. A área das 40 moradias destruídas foi declarada de risco e destinada à preservação permanente. 0 mesmo aconteceu com o terreno onde funcionava a Escola Tiradentes ${ }^{4}$. Tentativas de mitigação foram previstas para a localidade, mas nunca saíram do papel. As ações travaram na incompetência pública.

Em 2009, a comunidade Pedro Krauss, além de outras três (Araranguá, Zendron e Garuva), foi contemplada com o Programa Novo Lar. Os recursos, no valor de R\$ 42 milhões, eram advindos do Orçamento Operacional do Fundo de Garantia por Tempo de Serviço, referentes à área orçamentária de habitação popular. "O programa seria realizado em áreas danificadas pela tragédia climática de 2008 [...]. Cerca de 4 mil famílias [...] seriam beneficiadas com obras e serviços voltados à segurança, habitação e regularização fundiária [...]" (Amaral \& Silva, 2013, p. 1). No entanto, em janeiro de 2013, o recurso foi devolvido pela Prefeitura à Caixa

\footnotetext{
${ }^{4}$ Passados cinco anos, os alunos da Pedro Krauss ainda necessitam deslocar-se até as antigas dependências da Escola Estadual Pedro II, no centro da cidade, cedidas pelo Estado para uso do município.
} 


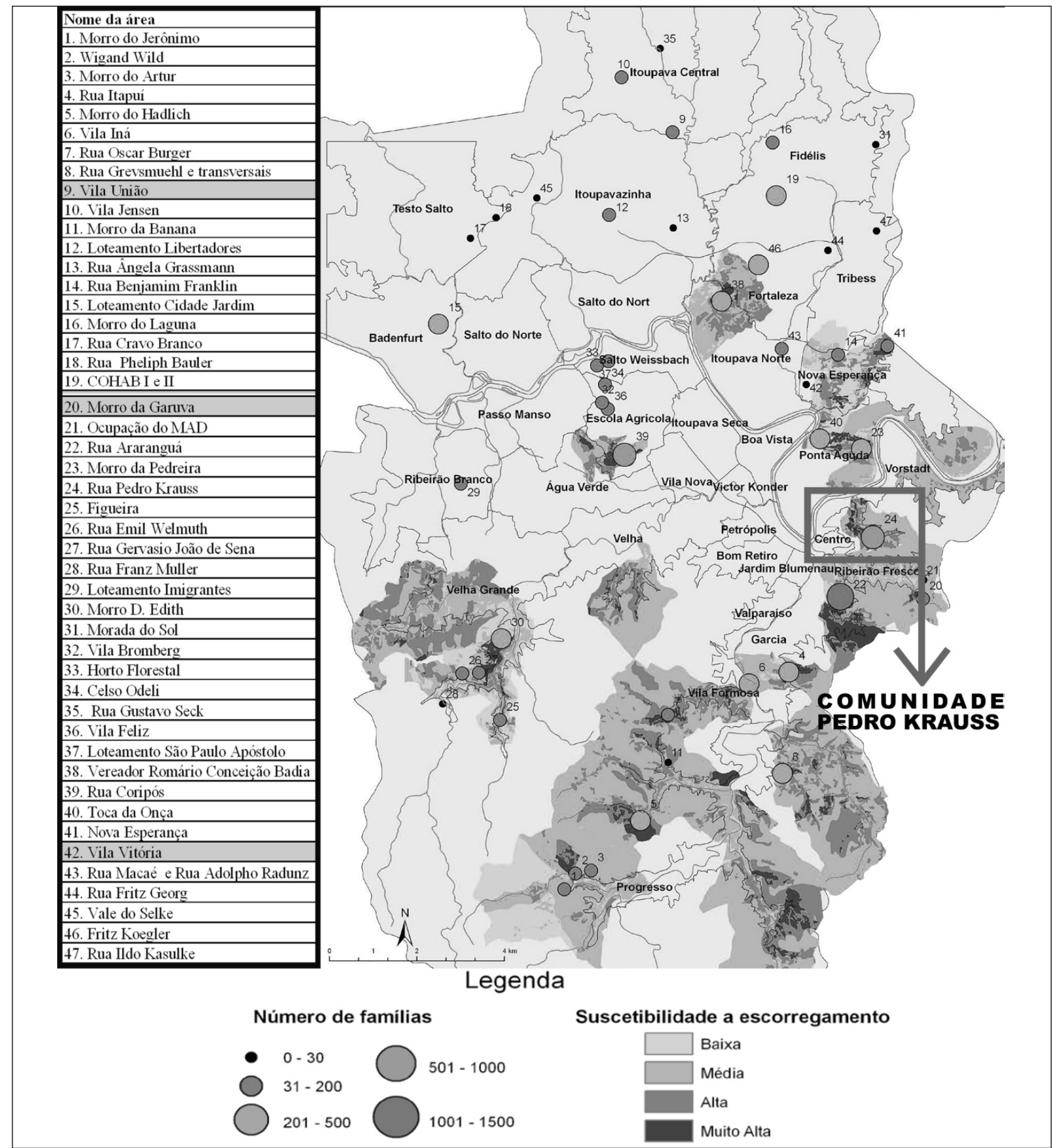

Figura 2 - Localização da comunidade no mapa do município com sobreposição de áreas suscetíveis a escorregamentos Fonte: Adaptado de Samagaia $(2010$, p. 123).

Econômica Federal por falta de projeto e utilização. 0 prazo para apresentação e gasto dos saldos depositados era até dezembro de 2012 (Gonçalves, 2013).

Em 24 de junho de 2010, o PMCMV teve resolução aprovada no Conselho Municipal de Habitação e
Interesse Social ${ }^{5}$, ratificando critérios de acesso. As moradias demoraram a sair porque a política de habitação nunca foi prioridade em Blumenau.

${ }^{5}$ Resolução no 004, de 24 de junho de 2010, do Conselho Municipal de Habitação e Interesse Social de Blumenau (BLUMENAU, 2010b). 


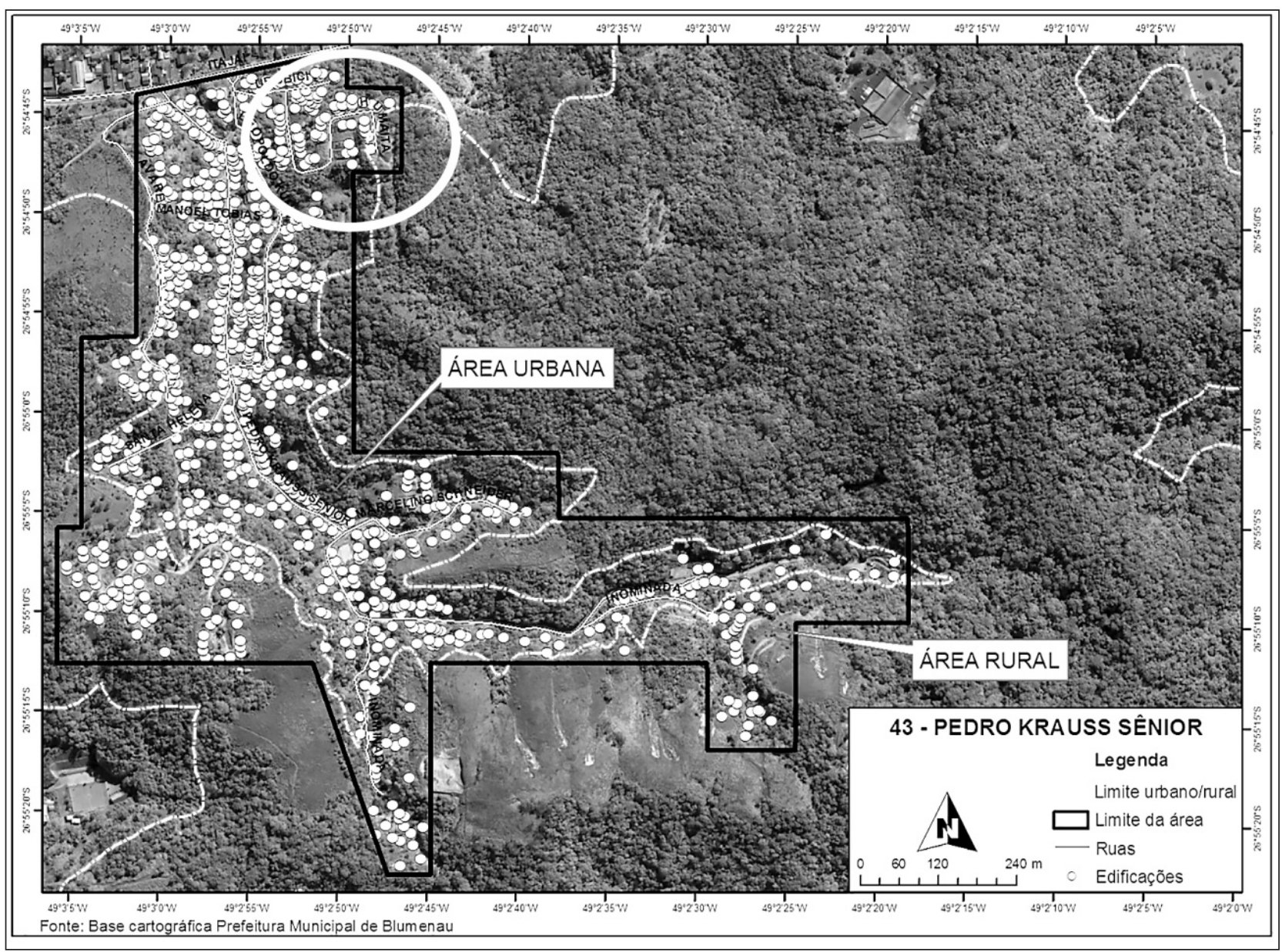

Figura 3 - Visão espacial da comunidade Pedro Krauss, com destaque para a localidade onde 40 famílias foram retiradas Fonte: PMHIS - Leitura Técnica (Blumenau, 2012, p. 203).

Os primeiros empreendimentos foram entregues somente em novembro de 2010, dois anos após o desastre (Voigt, 2010). Famílias da Pedro Krauss acessaram apartamentos nesses condomínios. No entanto, o déficit habitacional da Pedro Krauss em 2012 ainda era de 248 moradias (Blumenau, 2012).

A Associação Beneficente Palmeira da Paz (ABPP) construiu um prédio (Residencial Mãos Dadas) com 16 apartamentos na comunidade, no qual residem famílias que perderam suas moradias no desastre. 0 prédio foi construído e mobiliado com recursos do próprio grupo. Mas nem tudo foi doado. 0 terreno foi liberado pela Prefeitura e é pago mensalmente pelos moradores. 0 residencial foi entregue no dia 2 de setembro de 2012. A seleção das famílias ocorreu por meio dos critérios estabelecidos em Decreto Municipal para acesso aos programas governamentais de moradia. "Cada família assinou um contrato de compra e venda, através do qual pagará valor mensal por 180 meses ao Fundo Municipal de Habitação de Blumenau [...]" (Artigas, 2012, p. 1). Conforme Wagner (2013, p. 1), para a população há descompromisso do Estado: "Necessitamos de compromisso público com uma gestão de política habitacional eficiente para a demanda, com [...] agilidade para regulamentação fundiária e interesse social [...]". 0 Estado age com descaso e de forma isolada, e a população procura encontrar soluções sozinha ou com ajuda da sociedade civil.

\section{A Gestão do risco de desastres}

O Estatuto da Cidade (Lei ${ }^{\circ} 10.257$, de 10 de julho de 2001) prevê que a operacionalização das políticas urbanas e habitacionais, assim como o debate sobre a gestão dos desastres, tenha a participação da população e da comunidade científica. 0 art. $2^{\circ}$, inciso II, prevê a “[...] gestão democrática por meio da participação 


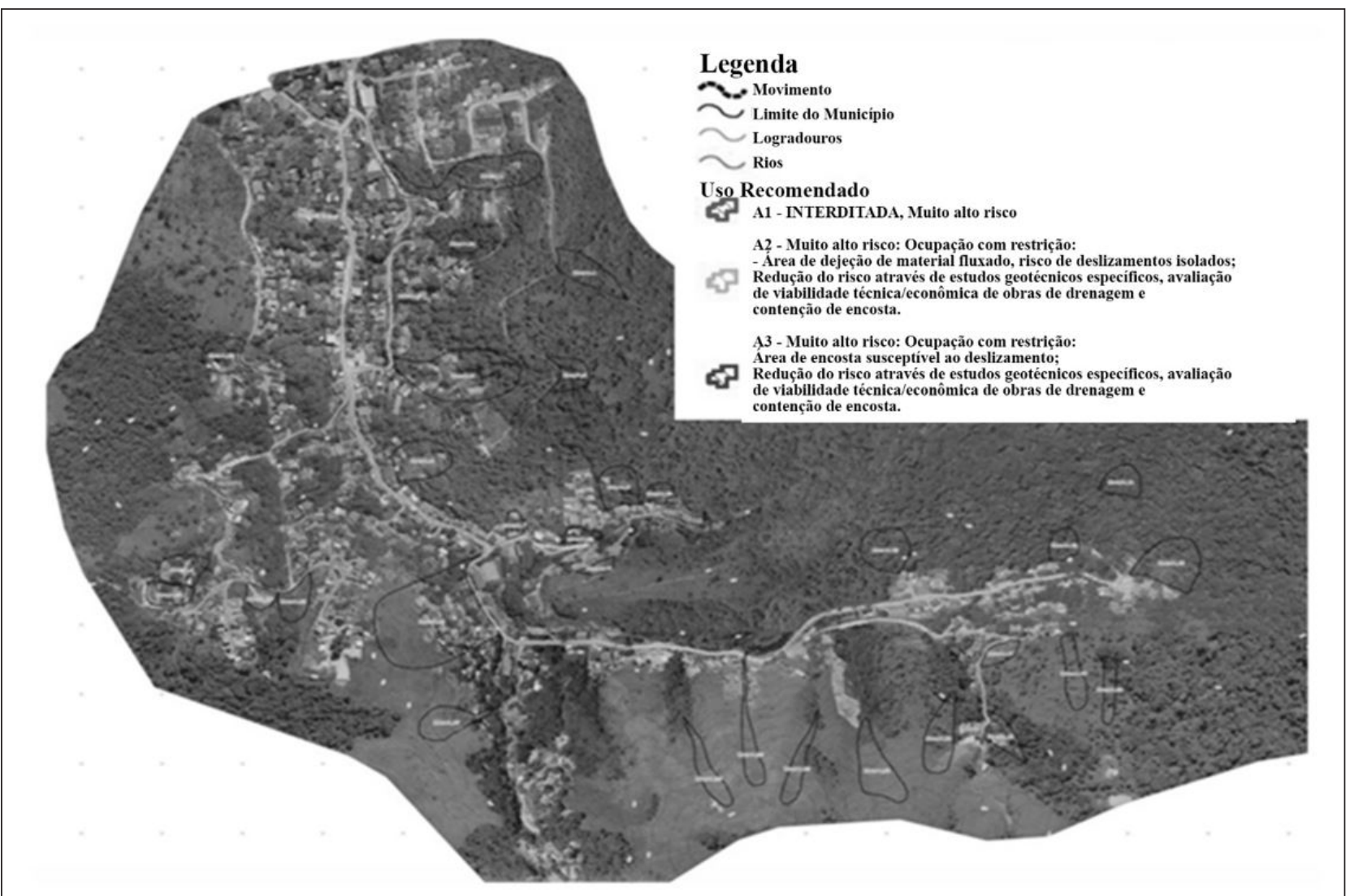

Figura 4 - Carta de uso recomendado do solo da Pedro Krauss

Fonte: PMHIS - Leitura Técnica (Blumenau, 2012, p. 204).

da população e de associações representativas dos vários segmentos da comunidade na formulação, execução e acompanhamento de planos, programas e projetos de desenvolvimento urbano [...]" (Brasil, 2001). A universidade pesquisa e produz material científico sobre o tema; a população busca respostas; o Estado atua de forma centralizada e isolada; ou seja, não existe interação entre os polos. Conforme Macedo (2013, p. 19) ${ }^{6}$ :

[...] a maior parte das políticas públicas setoriais brasileiras (Habitação, Saneamento Básico, Educação, Desenvolvimento Regional, Assistência Social), ignoram a importância da componente "riscos e desastres" em suas diretrizes e linhas de ação. [...] Isso tem dificultado a formação de uma cultura de prevenção, cujo sucesso depende de ações com efeito sinérgico sobre os vários fatores geradores dos riscos.

\footnotetext{
${ }^{6} \mathrm{O}$ autor é geólogo do Instituto de Pesquisas Tecnológicas (IPT) de São Paulo.
}

Em Blumenau, houve avanços após 2008. Os planos de contingência da Defesa Civil (Blumenau, 2015) e da Assistência Social (Blumenau, 2014), que até então tratavam apenas das situações de emergência causadas por enchentes ${ }^{7}$, incorporaram deslizamentos e escorregamentos em suas diretrizes de ação. 0 plano de contingência da Defesa Civil tem por objetivo:

[...] estabelecer atribuições [...] visando a minimização do desastre, nas fases de prevenção e preparação e o restabelecimento das condições de normalidade nas fases de resposta e reconstrução, frente aos eventos adversos, inundação gradual (enchente), inundação brusca (enxurrada) e escorregamentos de solo (Blumenau, 2015, p. 2).

\footnotetext{
${ }^{7}$ No passado, ocorriam apenas enchentes em Blumenau. Em 2008, no entanto, ocorreram enchentes associadas a enxurradas, deslizamentos e escorregamentos. Portanto os planos de contingência da Defesa Civil (Blumenau, 2015) e da Assistência Social (Blumenau, 2014) necessitaram de adaptações à nova realidade.
} 
O plano de contingência da Assistência Social (Blumenau, 2014, p. 2) "[...] visa estabelecer os procedimentos a serem adotados [...], quando da atuação direta ou indireta em eventos relacionados a desastres naturais e tecnológicos [...]". Embora as respostas configurem-se em três processos distintos, mas interdependentes - pré, trans e pós-impacto -, conforme a Figura 5, as ações ainda são mais focadas na gestão de desastres (campo das respostas e recuperação) do que na gestão do risco de desastres.

Historicamente em Blumenau e região:

As ações governamentais para se defender dos desastres geralmente se deram [...] através de obras hidráulicas (barragens e "melhoramento" fluvial), como se fossem a questão essencial do problema, desconsiderando regras de uso do solo, desmatamentos, formas de ocupação como fatores essenciais para a constituição e o agravamento dos desastres. Nesta linha de reflexão, Mattedi (1999, p. 13) [...] defende a idéia [sic] de que padrões de intervenções governamentais que se consolidaram ao longo do tempo, partiram de uma configuração segmentada e parcial do problema das enchentes e desastres, acabando por agravá-lo em função da produção de uma falsa imagem de segurança (Samagaia, 2010, p. 103).

Ou seja, as ações governamentais e de gestão dos desastres se dão mais no campo das medidas estruturais em detrimento das não estruturais. Conforme Samagaia (2010, p. 103):

A população geralmente percebe tais obras como necessárias, por falta de conhecimento técnico do problema e também de reconhecimento da dimensão política que implicam. Chama-se a atenção neste sentido para as formas centralizadas de decisão sobre a utilização do espaço e de recursos em Blumenau, visto que quase sempre as decisões são tomadas sem participação da sociedade organizada.

O Marco de Hyogo (UNISDR, 2005, p. 4) alerta para a:

[...] importancia de lograr la participación de todos los interesados, en particular los gobiernos, las instituciones financieras y las organizaciones regionales e internacionales, la sociedad civil, incluidas las organizaciones

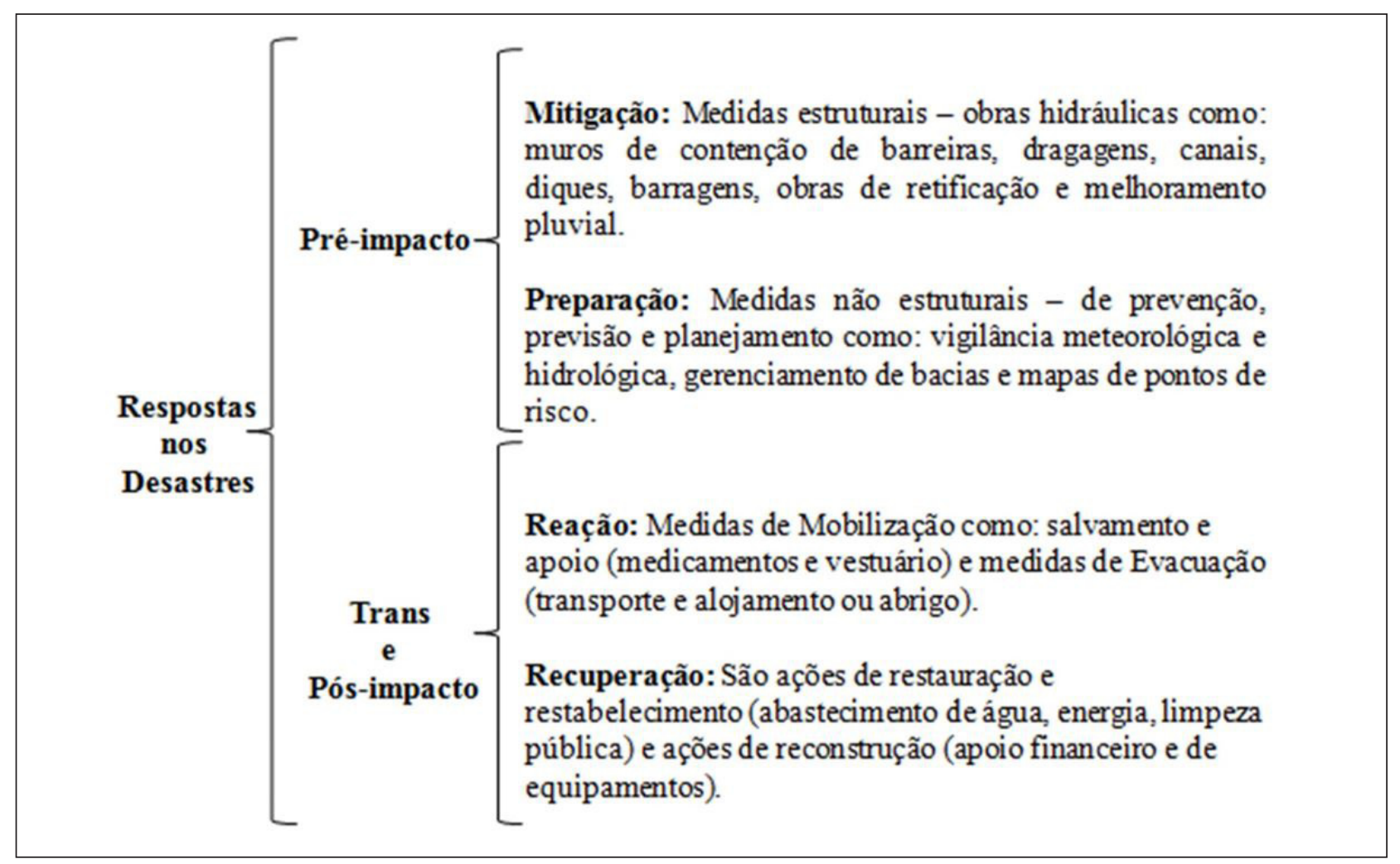

Figura 5 - Quadro das respostas governamentais nos desastres

Fonte: Elaboração dos autores (2015). Adaptado de Mattedi (1999, p. 165). 
no gubernamentales y los voluntarios, el sector privado y la comunidad científica.

A necessidade da participação comunitária no processo decisório da gestão também é apontada por Sachs (1993). Para o autor, “[...] o principal desafio é reconhecer as novas configurações políticas e trabalhar em busca de uma democracia participativa em todos os níveis local (rural e urbano), nacional e global [...]" (Sachs, 1993, p. 175). O Marco de Hyogo (UNISDR, 2005, p. 8) elenca estratégias de ação pertinentes para a prevenção de desastres, as quais se dão no campo da:

a) Gobernanza: marcos institucionales, jurídicos y normativos;

b) Identificación, evaluación y vigilancia de los riesgos $y$ alerta temprana;

c) Gestión de los conocimientos y educación;

d) Reducción de los factores de riesgo subyacentes;

e) Preparación para una respuesta eficaz y una recuperación efectiva.

O Marco de Sendai (ONU, 2015, p. 5) amplia a discussão, lançando desafios futuros na perspectiva de redução do risco de desastres. Conforme aponta:

Deve haver uma abordagem mais ampla e centrada nas pessoas para prevenir os riscos de desastres. As práticas de redução do risco de desastres precisam ser multissetoriais e orientadas para uma variedade de perigos, devendo ser inclusivas e acessíveis para que possam se tornar eficientes e eficazes. Reconhecendo seu papel de liderança, regulamentação e coordenação, os governos devem envolver as partes interessadas, inclusive mulheres, crianças e jovens, pessoas com deficiência, pessoas pobres, migrantes, povos indígenas, voluntários, profissionais da saúde e idosos na concepção e implementação de políticas, planos e normas. É necessário que os setores público e privado e organizações da sociedade civil, bem como academia e instituições científicas e de pesquisa, trabalhem em conjunto e criem oportunidades de colaboração, e que as empresas integrem o risco de desastres em suas práticas de gestão.

Nesse contexto, a questão política torna-se elemento essencial para reduzir a vulnerabilidade e o risco.
Não basta atuar na emergência com medidas de mitigação do impacto. Faz-se necessário pensar medidas e firmar compromissos a longo prazo. Muitas vezes, a ação na emergência camufla a ameaça, prejudicando iniciativas e investimentos institucionais orientados à redução do risco de desastres; ou, ainda, aumenta a vulnerabilidade e diminui a capacidade das pessoas para avaliar e antecipar-se a potenciais ameaças. Atuar na perspectiva de redução do risco de desastres é uma questão política e envolve a criação e a implementação de políticas públicas em todos os níveis de governo. As ações devem ser integradas entre as diversas políticas sociais (saúde, habitação, agricultura, assistência social, meio ambiente, desenvolvimento etc.), em base relacional e integrada entre Estado e sociedade civil organizada, valorizando os saberes locais (ISDR, 2004, p. 21).

O Marco de Sendai (ONU, 2015, p. 6) sintetiza ações que se fazem necessárias para reduzir o risco de desastres. Conforme o texto:

[...] é necessário enfrentar os atuais desafios e se preparar para os futuros, com foco em: monitoramento, avaliação e compreensão do risco de desastres e compartilhar essas informações e como elas são geradas; fortalecimento da governança do risco de desastres e coordenação entre as instituições e os setores relevantes, bem como a participação plena e significativa das partes interessadas nos níveis adequados; investimento na resiliência econômica, social, de saúde, cultural e educacional de pessoas, comunidades e países e no meio ambiente, inclusive por meio de tecnologia e pesquisa; melhoria em sistemas de alerta precoce para vários perigos, preparação, resposta, recuperação, reabilitação e reconstrução.

Para isso, o conhecimento científico e os saberes locais precisam ser reconhecidos e integrados às ações do Estado, do mesmo modo que os munícipes devem perceber-se como cidadãos de direitos e coparticipantes do processo decisório, e o Estado reconhecê-los como tal.

\section{Considerações finais}

Vimos que a lógica de ocupação do espaço e a utilização dos recursos determinaram o padrão de desenvolvimento urbano e socioeconômico da região do Vale do Itajaí. 
O processo histórico da produção da vulnerabilidade passa pelo desenvolvimento socioeconômico e ações governamentais no enfrentamento da problemática. Respostas inadequadas aumentam o impacto dos desastres sobre a população atingida, elevando sua vulnerabilidade. Os desastres estão relacionados também a componentes culturais e sociais. As práticas tradicionais e as normas culturais e familiares podem aumentar a vulnerabilidade aos desastres de algumas parcelas da população, como as mulheres, idosos e crianças. Influem também na forma de a população perceber e compreender o risco, o qual aumenta a suscetibilidade de uma comunidade ao impacto dos desastres, mas permite repensar a sociedade e atuar de forma ativa e organizada na gestão. Portanto a solução passa pela política e também pela interação e intercâmbio de informações entre os diferentes níveis de gestão.

Concluímos que há relação entre desastre e o desenvolvimento socioeconômico de uma região e, o desenvolvimento não deve ser visto somente a partir da ótica econômica, mas também dos aspectos sociais, culturais, políticos, ambientais e territoriais. Os desastres exigem respostas adequadas para o seu enfrentamento, bem como políticas públicas que sejam capazes de integrar os diversos atores sociais (poder público, comunidade científica e comunidade local), que estabeleçam relações com a sociedade, que tenham como enfoque o território e o planejamento, que valorizem a dinâmica local e que incorporem à política de gestão a participação comunitária (gestão participativa).

É urgente a capilarização das ações de gestão do risco, a atuação preventiva, a descentralização do processo decisório, a manutenção da interface entre todas as esferas governamentais, o conhecimento científico e a população, considerando os saberes locais. As estratégias para a redução e gestão do risco de desastres requerem vontade política e passam pela mudança de paradigmas em todos os níveis de gestão.

\section{Referências}

Amaral, N., \& Silva, S. (2013). Blumenau assina contrato para executar Programa Novo Lar. Blumenau: Prefeitura Municipal. Recuperado em 06 de março de 2015, de http://www. comentarium.com.br/blog-post.jsp?blogPostID=1887511
Artigas, A. (2012). Residencial mãos dadas será entregue às famílias no próximo domingo. Blumenews. Recuperado em 30 de agosto de 2012, de http://www. blumenews.com.br/site/index.php/comunidade/social/ item/1607residencialm\%C3\%A3os-dadas-ser\%C3\%A1 entregue $\%$ C3\%A0sfam\%C3\%ADliasnopr\%C3\%B3ximo domingo

Aumond, J., \& Sevegnani, L. (2009). Medidas de estabilização de encostas. In B. Fran, \& L. Sevegnani (Orgs.). Desastre de 2008 no Vale do Itajaí: água, gente e política (p. 79-91). Blumenau: Agência de Água do Vale do Itajaí.

Avila, M. R. R., \& Samagaia, J. (2013). Reconhecimento e caracterização das áreas de concentração de pobreza em Blumenau/SC (Relatório Final de Pesquisa/FUMDES/ Art. 171). Blumenau: Fundação Universidade Regional de Blumenau.

Avila, M. R. R., Oliveira, J. G. B., Silva, J. M. M., Sousa, C. M. M., \& Santos, G. F. (2014). TERRITÓRIO OCULTO: o escondimento da pobreza em Blumenau. In Anais do II Seminário Nacional de Planejamento e Desenvolvimento (p. 1-20). Florianópolis: Programa de Pós-graduação em Planejamento e Gestão Pública - PPGPGP. Recuperado em 15 de março de 2015, de http://www.eventos.ct.utfpr. edu.br/anais/snpd/pdf/snpd2014/706.pdf

Beck, U. (1997). A reinvenção da política: rumo a uma teoria da modernização reflexiva. In U. Beck, A. Giddens \& S. Lasch. Modernização reflexiva: política, tradição e estética na ordem social moderna (264p.). São Paulo: Ed. da UNESP. Recuperado em 23 de junho de 2014, de http://pt.scribd.com/doc/53016604/ Modernizacao-Reflexiva-Giddens-Beck-e-Lash

Blumenau. (2008, 17 de novembro). Código Estadual do Meio Ambiente. Jornal Santa Catarina.

Blumenau. Prefeitura Muncipal. Secretaria de Planejamento Urbano - SEPLAN. (2010a). Bairro Vorstadt. Perfil dos bairros. Blumenau: Prefeitura Municipal. Recuperado em 22 de março de 2015, de http://www.blumenau.sc.gov.br/ downloads/seplan/perfil_bairros/bairro_valparaiso.pdf Blumenau. Prefeitura Municipal. (2010b, 24 de junho). Resolução n. 004 do Conselho Municipal de Habitação e Interesse Social. Blumenau: Prefeitura Municipal. Recuperado em 12 de março de 2015, de: http://www. blumenau.sc.gov.br/downloads/semascri/resolucao_ conselho_habitacao_004.pdf 
Blumenau. Prefeitura Municipal. Secretaria Municipal de Habitação e Regularização Fundiária. (2012). Plano Municipal de Habitação e Interesse Social - PMHIS: Etapa II - Diagnóstico do Setor Habitacional: Inserção Regional e Caracterização Municipal. In Blumenau. Prefeitura Municipal. Secretaria Municipal de Habitação e Regularização Fundiária. PMHIS - Leitura Técnica (p. 1-302). Blumenau: Prefeitura Municipal.

Blumenau. Secretaria de Desenvolvimento Social SEMUDES. (2014). Plano de Contingência da SEMUDES: serviço de proteção e situações de calamidades públicas e de emergências. Blumenau: Prefeitura Municipal.

Blumenau. Prefeitura Municipal. Secretaria Municipal de Defesa Civil - SEDEF. (2015). Plano de continência inundações e escorregamentos - Anexo A: normas gerais de ação. Blumenau: Prefeitura Municipal.

Bohn, N., Silva, V., \& Revian, E. C. (2009). A responsabilidade civil do estado por omissão frente ao desastre. In B. Frank, \& L. Sevegnani (Orgs.), Desastre de 2008 no Vale do Itajaí: água, gente e política (p. 157-165). Blumenau: Agência de Água do Vale do Itajaí.

Brandão, C. A. (2004). Teorias, estratégias e políticas regionais e urbanas recentes: anotações para uma agenda do desenvolvimento territorializado. Revista Paranaense de Desenvolvimento, 107, 57-76.

Brasil. (2001, 11 de julho). Lei no 10.257, de 10 de julho de 2001. Regulamenta os arts. 182 e 183 da Constituição Federal, estabelece diretrizes gerais da política urbana e dá outras providências. Brasília: Diário Oficial da União. Recuperado em 08 março de 2015, de http://www. planalto.gov.br/ccivil_03/leis/leis_2001/110257.htm

Collins, A. E. (2009). Disaster and development. London: Routledge Taylor \& Francis Group.

Costa Gomes, P. C. (1995). 0 conceito de região e sua discussão. In L. E. Castro, \& P. C. Costa Gomes. Geografia, conceitos e temas (p. 49-76). Rio de Janeiro: Bertrand Brasil.

Dauphiné, A., \& Provitolo, D. (2013). Risques et Catastrophes: Observer, Spatialiser, Comprendre, Gérer (2. ed.). Paris: Armand Colin.

Frank, B., \& Sevegnani, L. (Orgs.) (2009). Desastre de 2008 no Vale do Itajaí: água, gente e política. Blumenau: Agência de Água do Vale do Itajaí.

Gonçalves, A. (2013, 01 de janeiro). Dinheiro público pelo ralo: Prefeitura de Blumenau perde financiamento de R 177 milhões. Informe Blumenau. Recuperado em 04 de março de 2015, de http://m.ndonline.com.br/vale/ colunas/informeblumenau/42790-dinheiro-publicopelo-ralo.html

Guia Santa Catarina. (2013). Localização/Geografia/ Blumenau. Recuperado em 05 março de 2015, de http:// www.guiasantacatarina.com.br/blumenau/cidade.php3

Hewitt, K., \& Burton, I. (1971). The hazardousness of a place: a regional ecology of damaging events. Toronto: University of Toronto.

Instituto Brasileiro de Geografia e Estatística - IBGE. (2014). Cidades/Santa Catarina/Blumenau. Brasília: IBGE. Recuperado em 17 de março de 2015, de http://www. cidades.ibge.gov.br/xtras/perfil.php?lang $=\& \operatorname{codmun}=4$ 20240\&search=santacatarna|blumenau

International Strategy for Disaster Reduction - ISDR. (2004). Living with Risk: a global review of disaster reduction initiatives. New York: ISDR. Recuperado em 23 de março de 2015, de http://www.unisdr.org/files/657_lwr1.pdf

Jornal Metas - JM. (2009, 25 de novembro). 365 Depois. Especial um ano da tragédia [Edição Especial]. Recuperado em 17 de março de 2015, de http://www.adjorisc.com. br/polopoly_fs/1.57785.1268867893!/menu/standard/ file/Jornal_Metas_-_365_dias_depois.pdf

Macedo, E. S. (2013, 23 de agosto). Gestão de Riscos no Brasil. In Rio Bonsai 2013. Seminário Internacional sobre prevenção de desastres naturais. (p. 1-41). Rio de Janeiro. Recuperado em 08 de fevereiro de 2017, de https:// www.jica.go.jp/brazil/portuguese/office/news/2013/ c8h0vm00007iqs1e-att/c8h0vm00007iqs4h.pdf

Mamigonian, A. (1966). Estudo geográfico das indústrias de Blumenau. Revista Brasileira de Geografia, ano XXVII(3), 389-481.

Mattedi, M. A. (1999). As enchentes como tragédias anunciadas: impacto da problemática ambiental nas situações de emergência em Santa Catarina (Tese de doutorado). Programa de Pós-graduação em Ciências Sociais, Instituto de Filosofia e Ciências Humanas, Universidade Estadual de Campinas, Campinas.

Mattedi, M. A. (2015). Pensando com o Desenvolvimento Regional: subsídios para um programa forte em Desenvolvimento Regional. Revista Brasileira de Desenvolvimento Regional, 2(2), 59-105. http://dx.doi. org/10.7867/2317-5443.2014v2n2p059-105. 
Mattedi, M. A., Frank, B., Sevegnani, L., \& Bohn, N. (2009). O desastre se tornou rotina... In: B. Frank, \& L. Sevegnani (Orgs.). Desastre de 2008 no Vale do Itajaí: água, gente e política (p. 13-21). Blumenau: Agência de Água do Vale do Itajaí.

Organização das Nações Unidas - ONU. (2015). Marco de Sendai para la Reducción del Riesgo de Desastres 20152030. Genebra: UNISDR. Recuperado em 05 de outubro de 2015, de https://www.unisdr.org/files/43291_ spanishsendaiframeworkfordisasterri.pdf

Phillips, B., Thomas, D. S. K., Forthergill, A., \& Blinn-Pike, L. (2010). Introduction. In B. D. Phillips, D. S. K. Thomas, A. Fothergill, \& L. Blinn-Pike (Eds.), Social vulnerability to disasters (p. 1-27). London: Taylor \& Francis Group.

Programa Minha Casa Minha Vida - PMCMV. (2013). Recursos FAR. Brasília: Caixa Econômica Federal. Recuperado em 14 de março de 2015, de http://www1.caixa.gov.br/gov/ gov_social/municipal/programas_habitacao/pmcmv/

Queiroz, A. D. (2009). Prefácio. In B. Frank, \& L. Sevegnani (Orgs.), Desastre de 2008 no Vale do Itajaí: água, gente e política. Blumenau: Agência de Água do Vale do Itajaí.

Sachs, I. (1993). Estratégias de Transição para o Século XXI, desenvolvimento e meio ambiente. São Paulo: Studio Nobel.

Salatiel, J. R. (2011, 21 de janeiro). Tragédia no Rio: o maior desastre natural do País. Uol Vestibular. Recuperado em 24 de outubro de 2015, de http://vestibular.uol.com. $\mathrm{br} /$ resumo-das-disciplinas/atualidades/tragedia-no-rioo-maior-desastre-natural-do-pais.htm

Samagaia, J. (2010). Globalização e Cidade: reconfigurações dos espaços de pobreza em Blumenau/SC (Tese de doutorado). Programa de Pós-graduação em Geografia, Universidade Federal de Santa Catarina, Florianópolis.

Samagaia, J., \& Angioni, M. (2009). Situação dos desabrigados/ atingidos pelo desastre e a assistência (des)organizada. In B. Frank, \& L. Sevegnani (Orgs.). Desastre de 2008 no Vale do Itajaí: água, gente e política (p. 138-146). Blumenau: Agência de Água do Vale do Itajaí.

Santos, M. (1978). Por uma geografia nova. São Paulo: Hucitec.

Santos, M. (1994). Técnica espaço tempo. São Paulo: Hucitec.

Santos, R. D. (2012). Gestão de desastres e Política de Assistência Social: estudo de caso de Blumenau/SC (Tese de doutorado). Programa de Pós-graduação em
Sociologia Política, Centro de Filosofia e Ciências Humanas, Universidade Federal de Santa Catarina, Florianópolis.

Schiochet, V. (2009). A ação governamental frente ao desastre. In B. Frank, \& L. Sevegnani (Orgs.). Desastre de 2008 no Vale do Itajaí: água, gente e política (p. 138-155). Blumenau: Agência de Água do Vale do Itajaí.

Sevegnani, L., Frank, B., \& Negredo, J. C., Soares, M. V., \& Keim, E. J. (2009). Gente socorrendo gente. In B. Frank, \& L. Sevegnani (Orgs.). Desastre de 2008 no Vale do Itajaí: água, gente e política (p. 110-127). Blumenau: Agência de Água do Vale do Itajaí.

Severo, D. L. (2009). A metereologia do desastre. In B. Frank, \& L. Sevegnani (Orgs.). Desastre de 2008 no Vale do Itajaí: água, gente e política (p. 70-77). Blumenau: Agência de Água do Vale do Itajaí.

Siebert, C. (2009). (Des)controle urbano no vale do Itajaí. In B. Frank, \& L. Sevegnani (Orgs.). Desastre de 2008 no Vale do Itajaí: água, gente e política (p. 38-51). Blumenau: Agência de Água do Vale do Itajaí.

Tachini, M. (2009). Descrição do desastre: a inundação. In B. Frank, \& L. Sevegnani (Orgs.). Desastre de 2008 no Vale do Itajaí: água, gente e política (p. 102-109). Blumenau: Agência de Água do Vale do Itajaí.

The United Nations Office for Disaster Risk Reduction UNISDR. (2005, 18 a 22 de enero). Hyogo Quadro de Acção (HFA). Geneva: UNISDR. Recuperado em 05 de outubro de 2015, de http://www.unisdr.org/we/coordinate/hfa

Valêncio, N, Siena, M., Marchezini, V., \& Lopes, D. C. (2007). 0 desastre como desafio para a construção de uma hermenêutica dialógica entre o Estado e os afetados. Revista Cronos, 8(1), 81-100.

Voigt, J. (2010, 11 de novembro). Primeiras moradias para famílias vítimas da tragédia são entregues em Blumenau. $O$ Barriga Verde. Recuperado em 08 de março de 2015, de http://www.adjorisc.com.br/cmlink/ homologaco/2.623/2.624/associados/obarrigaverde/ cidadania/primeiras-moradiasparafamiliasvitimasdatr agediasoentreguesemblumenau 1.368420

Wagner, A. G. (2009). Custos da recuperação, contabilização dos prejuízos e impactos na economia regional. In B. Frank, \& L. Sevegnani (Orgs.). Desastre de 2008 no Vale do Itajaí: água, gente e política (p. 128-137). Blumenau: Agência de Água do Vale do Itajaí. 
Wagner, O. V. (2013, 31 de agosto). Comentário publicado em 31 de agosto de 2013 sobre matéria "Residencial Mãos Dadas será entregue às famílias no próximo domingo" de A. Artigas. Blumenews. Recuperado em 06 de março de 2015, de http://www.blumenews.com.br/site/index.php/ comunidade/social/item/1607residencialm\%C3\%A3osdadas-ser $\%$ C3\%A1entregue $\%$ C3\%A0sfam $\%$ C3\%ADlias nopr\%C3\%B3ximodomingo
Walter, F. (2008). Catastrophes: une histoire culturelle: XVI-XXI siècle. Paris: Éditions Du Seuil.

Waltrick, R. (2008, 23 de novembro). Flagelo da chuva: tempo castiga a região [Coluna Geral]. Jornal Santa Catarina, 19.

Recebido: Jul. 17, 2015

Aprovado: Maio 03, 2016 